\title{
LA MOVILIZACIÓN MILITAR EN NAVARRA DURANTE EL REINADO DE CARLOS II (1665-1700): FUEROS, SERVICIOS Y MILICIAS
}

\author{
Antonio José Rodríguez Hernández \\ UNED
}

\begin{abstract}
RESUMEN. El objetivo de este trabajo es analizar la movilización militar en Navarra, atendiendo a la importancia de los sistemas de movilización forales, la participación de las milicias, los servicios de tropas concedidos por las Cortes y el reclutamiento de voluntarios para incorporarse a otros ejércitos. La investigación se fundamenta en fuentes inéditas que se conservan tanto en los archivos nacionales como en los regionales. Gracias a esas fuentes se han reconstruido todos los procesos de movilización militar del periodo para analizar sus dinámicas, problemas y métodos. El hilo conductor es el análisis pormenorizado de los diversos sistemas de movilización militar presentes en Navarra durante el siglo XVII - tanto los amparados por los fueros, como los que quedaban al margen - ya fueran controlados por la Diputación del reino o los virreyes. Con ello se pretende comprender el encaje de Navarra en el sistema defensivo de la monarquía, su aportación humana, y sus repercusiones sobre la población.
\end{abstract}

Palabras clave: fueros, reclutamiento, milicias, frontera, Navarra

ABSTRACT. This paper studies the different ways of military mobilization the Hispanic Monarchy had in the Kingdom of Navarre. Just like in the rest of the Crown of Castile, troops could be recruited following the traditional system of commissioned officers and voluntary recruits. However, this Pyrenean territory had its own institutions —Diputación and Cortes-, and these were very zealous of its own local laws - fueros - Consequently, there were specific recruitment modalities regarding the raise of the local militias and the levy of new tercios, both under the scrutiny and mediation of the Cortes. This research, based on our work in regional and national archives, allows us to study the dynamics and problems seen between local institutions and the vice-regal authority in the context of the wars between Spain and France during the second half of the $17^{\text {th }}$ century. What we look for in this paper is to measure

Recibido: 18-11-2020 . Aceptado: 2-05-2021 . ajrodriguez@geo.uned.es 
Navarre's contribution to the general war effort, hence putting into question the Navarrese war effort given the particularities of its own institutions and the resulting tensions between the small kingdom and the central authorities.

Keywords: fueros, recruitment, militia, frontier, Navarre

LA HISTORIOGRAFÍA SOBRE LO MILITAR en Navarra durante los siglos XVI y XVII ha evolucionado durante las últimas décadas. A los estudios clásicos (Idoate, 1981), se han ido sumando otros que combinan las fuentes locales con los archivos nacionales (Gallastegui, 1990; Rodríguez Garraza, 1991 y 2007; Chavarría, 2006; Escribano, 2015). Trabajos que se suman a la fértil historiografía navarra, basada fundamentalmente en la documentación conservada en el Archivo General del Reino de Navarra (Coloma, 1995; Martínez Arce, 2002; Usunáriz, 2007; Floristán, 2015). Más recientemente, se han ido añadiendo otros trabajos que se centran en el reinado de Carlos II (Espino López, 2018; Rodríguez Hernández, 2018).

Siguiendo esta última línea, en este artículo analizamos las fórmulas de movilización militar practicadas en Navarra durante el reinado de Carlos II (1665-1700). El punto de partida se encuentra en el comienzo de la Guerra franco-española (16351659). Atendiendo a lo que la historiografía ha estudiado previamente, hemos reconstruido los procesos de movilización militar que se desarrollaron en Navarra durante dicho periodo a partir de la documentación conservada en Navarra y de la remitida a los consejos de Estado y Guerra, contrastando los diversos puntos de vista de la problemática.

Durante este periodo Navarra siguió manteniendo sus instituciones propias. Para desarrollar este trabajo analizaremos las instituciones tradicionales, la evolución de la movilización foral en base a nuevas transformaciones de la práctica bélica, con la creación de los tercios de milicias, y el papel de las milicias fronterizas. Por último, analizaremos los servicios de tropas aprobados en Cortes, para después profundizar en el reclutamiento de tropas voluntarias por parte de la monarquía en Navarra.

\section{El apellido: Ilamamiento general a fuero}

El Fuero General disponía de un instrumento tradicional —el apellido_- por el cual los varones en edad militar — de entre 14 a 60 años_- podían ser convocados para defender Navarra en caso de invasión. Si el rey acompañaba a las huestes en persona, la movilización podía alargarse y sobrepasar los límites geográficos. Los hombres debían servir a su costa los primeros tres días. Posteriormente, el monarca debía asumir sus soldadas, pudiendo ser un llamamiento anual ${ }^{1}$. Este tipo de re-

1 Fuero General de Navarra, Libro I, Título I, cap. IV-V. (edición de 1869, Pamplona, Imprenta Provincial). 
clutamiento, denominado también «llamamiento general a fuero», es conocido por la historiografía (Idoate, 1981, pp.18-26; Floristán, 2015, pp.151-152), al ser una evolución del uso medieval (Fernández de Larrea, 1992, p. 37 y 2018, p. 183), que implicaba el apoyo de la Diputación (Salcedo, 1974, p. 436). Así, se podía reunir un gran número de hombres. Según el reino en solo dos días se podían reunir entre 2030.000 hombres. Este método había resultado efectivo en 1542 y 1558 (Idoate, 1981, pp.116-117 y 142-148), y se volvió a emplear en 1615, cuando el duque de Ciudad Real movilizó a 16.000 navarros para conseguir la concordia sobre las diferencias de términos en los montes Alduides. En 1636, el marqués de Valparaíso entró en Francia con 14.000 voluntarios ${ }^{2}$ — cifra que otras fuentes reducen a 12.000 - ocupando San Juan de Luz . Sin embargo, tras pocas semanas, los navarros entendieron que habían cumplido y regresaron a su casa, ya que servían sin sueldo. Es decir, el sistema servía para movilizar un gran volumen de tropas, con poco coste, pero por poco tiempo.

Vemos pues que en origen se trataba de un llamamiento de carácter defensivo, en contraposición con la hueste o fonsado (Pascual, 2003). El problema era que existían dos interpretaciones del fuero. Para los virreyes, los navarros tenían la obligación de servir al rey con sus propias armas si la situación lo requería. El reino, en cambio, entendía que salvo en caso de invasión, el servicio era voluntario, y solo podía ser aprobado por las Cortes (Usunáriz, 2007, p. 309). Navarra utilizaba en su argumentario el llamado Fuero Reducido (1528-1530), que no se llegó a promulgar, y que apuntaba que las Cortes debían votar la utilización de dichas fuerzas fuera del reino, mientras que la Corona se retrotraía al original que no hacía dicha puntualización (Jimeno, 2007, pp. 58-59).

Durante el reinado de Carlos II no se pidió la movilización general al no producirse una invasión a gran escala, a pesar de la creciente amenaza francesa. Eso no impidió que algunos virreyes intentaran poner los medios para una posible movilización. Durante el verano de 1668, se advirtió de los movimientos franceses al otro lado de la frontera ${ }^{4}$. El propio virrey visitó las defensas, y dio orden de juntar a los varones de entre 18 y 60 años para evitar «las invasiones que intente el orgullo francés» y confeccionar listados de las armas que faltaban para que las autoridades locales las proveyeran —algo que ya se había hecho en 1625, desembolsándose 50.000 duca-

2 Consulta del consejo de Guerra (en adelante CCG), 14 de agosto de 1684. Archivo General de Simancas (en adelante AGS), Guerra Antigua (en adelante GA), leg. 2610. Memorial del reino, Pamplona, 24 de abril de 1684. Archivo General del Reino de Navarra (en adelante AGRN), Guerra, leg. 5 nº 29.

3 Rey a Parma, Madrid, 1 de mayo y 17 de julio de 1676. AGS, GA, libro 331 f. 150 y 175v. Novíssima recopilación..., tomo I, pp. 149 y ss.

4 Consulta del consejo de Estado (en adelante CCE), 21 de julio de 1668. AGS, Estado (en adelante E), leg. 2687. CCE, 7 y 12 de abril de 1669. AGS, E, leg. 2688. CCE, 26 de enero de 1669. AGS, E, leg. 2543. 
dos para armar a todos 5 - La medida fue atacada por la Diputación por los gastos y molestias que ocasionaba, negándose a que el reino pagase las armas, alegando que hacía poco se había concedido un donativo ${ }^{6}$. La cuestión quedó detenida, pero esto no impidió que otros virreyes procediesen a averiguar el número de hombres disponibles. Así, en 1689 se confeccionó un informe sobre los varones de entre 14 y 60 años residentes en Pamplona capaces de luchar -2.015-, por si eran necesarios para defender la ciudad ${ }^{7}$.

\section{Los cuatro tercios de milicias}

Otra institución defensiva destacada fueron los cuatro tercios de milicias, organización que - aunque conocida por la historiografía (Idoate, 1981, p. 28-29; Rodríguez Garraza, 1991, p. 176; Floristán, 2015, p. 91)—, nunca se ha definido de manera precisa, probablemente por no ser controlado directamente por la Diputación. La movilización general de todos los varones en forma del apellido era molesta para los implicados, y poco útil, al realizarse en momentos puntuales de peligro extremo. Se reunían muchos hombres por poco tiempo, cuando lo que realmente necesitaban eran menos soldados durante más tiempo. Los esfuerzos realizados en 1636 hicieron pensar en una vía paralela para aliviar a los naturales, y en 1638 el marqués de los Vélez negoció que Navarra mantuviese 4.000 milicianos distribuidos en cuatro tercios, nombrando a los oficiales. En julio, cerca de 6.000 navarros fueron movilizados por el método tradicional para hacer frente a los franceses, que ese año quemaron Vera, participando la mayoría de ellos en el socorro de Fuenterrabía ${ }^{8}$. En la operación el contingente navarro ascendió a 4.500 infantes, acompañados por 500 nobles y algunos jinetes, si bien éstos llegaron unas pocas semanas antes de la victoria del ejército de Felipe IV (Usunáriz, 2012, p. 173; Floristán, 2015, p. 87). Al año siguiente estas tropas se mantuvieron en la región, ante el miedo a una invasión ${ }^{9}$. La situación cambiará en 1640, año que se enviaron dos de los cuatro tercios a la frontera aragonesa - aunque al principio se habían pedido los cuatro-, siendo las deserciones generalizadas (Rodríguez Garraza, 1991, pp. 157-58; Floristán, 1984, pp. 181-188). A comienzos de 1641 los tercios solo disponían de 269 soldados $^{10}$.

$5 \quad$ Novíssima recopilación ..., tomo I, pp. 154.

6 CCE, 12 de octubre de 1669. AGS, E, leg. 2689. Orden del virrey, Pamplona, 22 de marzo de 1669. Órdenes cursadas, Pamplona, 22 de marzo de 1669. Diputación al virrey, Pamplona, 29 de marzo de 1669. ARGN, Guerra, leg. 4 nº 46.

7 CCG, 11 y 29 de abril de 1689. AGS, GA, leg. 2791. Memoria de la noticia..., s/f. AGS, GA, leg. 2792

$8 \quad$ Novíssima recopilación..., tomo I, pp. 149 y 154.

9 Los Vélez al rey, Pamplona, 10 de marzo de 1639. CCG, 23 de febrero de 1639. AGS, GA, leg. 1257.

Relación de la infantería efectiva, Fraga, 11 de febrero de 1641. AGS, GA, leg. 1403. 
Las unidades se formaban por cupos repartidos entre las diversas jurisdicciones, pero sus naturales no tenían la obligación de salir del reino. Durante esos años la Diputación accedió a los llamamientos de la Corona debido a la situación extrema que se vivía, y por el hecho de que hacía bastante tiempo que no habían surgido otros llamamientos. A eso se sumaba — en palabras de la Diputación — «el amor de los navarros a sus reyes ${ }^{11}$. La anómala situación haría que desde las Cortes de 1642 las cosas cambiaran de manera decisiva, ya que éstas - a pesar de que la petición de la monarquía era la misma: 2.000 hombres para luchar en la frontera catalana-, concedieron un tercio de 1.300 pagado por unos meses (García Miguel, 1988, pp. 121-130). Daba comienzo la dinámica de los servicios de tropas aprobados en las Cortes. Desde esas fechas, los cuatro tercios de milicias se limitarían a defender Navarra en caso de que fuera necesario.

Los tercios aseguraban el resguardo del reino al poder apoyar a los profesionales que custodiaban Pamplona. Su número, teóricamente 4.000 hombres, era suficiente para cubrir los pasos con Francia, y su activación no era tan pesada para la población. Con ello se conseguían unidades manejables - de 10 a 11 compañías, con 100 efectivos de media-, con la misma estructura que las unidades profesionales, pero dirigidas por naturales. Las tropas solo cobraban cuando eran movilizadas $-\mathrm{si}$ bien, como el apellido, los primeros tres días servirían a costa de las comunidades a las que representaban - Los soldados eran aportados por cupos repartidos entre los municipios y servían por turnos. Esto hacía que no fueran bien vistos por las autoridades militares, ya que en otras partes los milicianos eran fijos y tenían más formación, de ahí que en ocasiones se enviasen oficiales reformados para instruir a los milicianos ${ }^{12}$. Los tercios estaban formados por soldados de «todas las ciudades, villas, valles, céndeas, y lugares de este Reyno, excepto los que son de la frontera para su defensa $\rangle^{13}$. Los oficiales gozaban de patentes reales, aunque solo cobraban su sueldo cuando salían a servir ${ }^{14}$, y gozaban del fuero militar ${ }^{15}$.

La movilización de los tercios tenía un coste en términos políticos. El virrey debía convencer a las autoridades de su necesidad, y lidiar con los contrafueros y quejas de la Diputación. La rapidez era clave, ya que se tardaba hasta 15 días en reunir a los hombres. Dentro de los alegatos utilizados para evitar la movilización, uno de ellos era instar a la monarquía a que reforzarse las defensas con dinero y profesio-

11 Memorial del reino, Pamplona, 24 de abril de 1684. AGRN, Guerra, leg. 5 n 29.

12 Juan Antonio López de Zarate a Navarra, Madrid, 29 de marzo de 1684. AGRN, Guerra, leg. $5 \mathrm{n}^{\circ}$ 23. Rey a Navarra, Madrid, 4 de abril de 1684. Juan Antonio López a Navarra, Madrid, 5 de abril de 1684. AGRN, Guerra, leg. 5 n 24.

13 Relación de la gente del presidio..., 19 de febrero de 1682. AGS, GA, leg. 2543.

14 Título a Francisco Sarabia, 7 de septiembre de 1655. AGS, GA, libro 251 f. $142 \mathrm{v}$.

15 CCG, 14 de agosto de 1684. AGS, GA, leg. 2610. Memorial del reino, Pamplona, 24 de abril de 1684. AGRN, Guerra, leg. 5 nº 29. 
nales — enviados desde Castilla— ${ }^{16}$. Algo que, en tiempos de crisis —y cuando las prioridades bélicas estaban en otras partes-, llegó a ser contestado por la monarquía recordando que «en las guerras pasadas, haviendo mas gente en España, se balieron los señores reyes, mis predecesores, de los naturales de esse reyno para la defensa de los pasos de las montañas», y que siendo en esos momentos las necesidades más grandes, era obligado valerse de los navarros para la defensa del reino ${ }^{17}$.

Los problemas y críticas hacia la movilización fueron comunes dentro de la media docena de veces que se intentó reunir a los tercios durante el reinado de Carlos II. Un buen ejemplo lo tenemos en 1674, año en que se dieron todos los pasos, aunque no terminó por efectuarse. El motivo del llamamiento era el nuevo enfrentamiento con Francia, dentro de la denominada Guerra de Holanda (1672-1678). En esos momentos se comenzaron a recibir informes que indicaban que los franceses acumulaban tropas para «infestar aquella frontera ${ }^{18}$. Los primeros despachos indicaban que en las provincias de Guyena y Labort se reunían 12.000 hombres. Nuevos informes aumentaron la cifra a 16.000 infantes — fundamentalmente milicianos-, y 4.000 caballos — entre gentileshombres y profesionales - , pensándose que su objetivo sería Fuenterrabía. Los contingentes se habían reunido para hacer frente a la armada holandesa, pero ésta se dirigía al Mediterráneo ${ }^{19}$. Para afrontar la crisis se pidió que las provincias fronterizas movilizaran a sus naturales ${ }^{20}$. Guipúzcoa cubrió los pasos fronterizos del Bidasoa, pagando y armando a 600 hombres - 400 en la frontera y 200 reforzando Fuenterrabía— ${ }^{21}$.

La movilización francesa hizo que Madrid ordenase el envío de refuerzos desde Castilla, y que el virrey previniera los cuatro tercios «sin el reparo de la quiebra de sus fueros $\gg^{22}$. El príncipe cursó distintas órdenes a las universidades para que fueran preparando las tropas, pero la Diputación contestó puntualizando los contrafueros, y quejándose de que la movilización solo estaba justificada si los franceses penetraban en el reino. La Diputación, además, señalaba el impacto sobre la economía, al coincidir con la cosecha. Finalmente, la movilización no se produjo, ya que pronto se demostró que el miedo a una invasión era infundado. La carta real indicaba que, a

16 CCE, 9 de enero de 1676. AGS, E, leg. 2701. CCE, 31 de enero, 25 de febrero, 30 de marzo, 30 de mayo, 25 de julio de 1676. AGS, E, leg. 2702. Diputación a Mariana, Pamplona, 9 de enero de 1676 Mariana a Navarra, Madrid, 27 de febrero de 1676. ARGN, Guerra, leg. 4 nº 55.

17 Rey a Parma, Madrid, 1 de mayo y 17 de julio de 1676. AGS, GA, libro 331 f. 150 y 175 v.

18 CCG, 22 de junio de 1674. AGS, GA, leg. 2302.

19 Parma al rey, Pamplona, 24 de mayo de 1674. CCG, 5, 1 y 22 de junio de 1674 . Noticias de la frontera, s/f. AGS, GA, leg. 2302. Parma al rey, Pamplona, 7 y 28 de junio de 1674. Religiosos del convento de Urdax al rey, 28 de junio de 1674. AGS, GA, leg. 2319.

20 CCE, 20 de junio de 1674. AGS, E, leg. 2698. CCG, 22 de junio de 1674. AGS, GA, leg. 2302.

21 CCG, 28 de junio de 1674. Guipúzcoa al rey, Hernani, 20 de junio y 5 de julio de 1674. AGS, GA, leg. 2302. Resumen de las cartas y lo resuelto, s/f. Guipúzcoa al rey, Hernani, 20 de junio de 1674. AGS, GA, leg. 2319. CCE, 4, 6 y 8 de julio de 1674. AGS, E, leg. 2699. 
pesar de la obligación de asistir con gente, ésta solo se produciría en caso de precisa necesidad $^{23}$. La reina regente agradeció las medidas, contestando la Diputación, sin aparente empacho, que «no se ha reservado porción alguna de la sangre de las naturales» ${ }^{24}$.

Los cuatro tercios de milicias fueron movilizados en 1689, al inicio de la Guerra de los Nueve Años (1689-1697) ${ }^{25}$, lo que conllevó quejas dentro de los representantes de los Tres Estados. Estos enviaron al virrey tres memoriales consecutivos, en los que se exigía sobreseer la formación, al ser convocados sus efectivos el 12 de mayo en Pamplona. Justificaban su petición con base en la esterilidad de la tierra, la necesidad de brazos en el campo y el miedo a que los franceses se sintiesen provocados. Esto fue contestado por el duque de Bournonville, expresando que la medida se justificaba por la propia conservación del reino. Los pasos debían ser ocupados para impedir a los franceses lo propio, y más cuando se sabía que éstos ya habían movilizado sus tropas, habían pasado muestra a las milicias de Labort y Bearne, y habían convocado el arrière ban en Bayona. Los memoriales del reino fueron elevados a Madrid, siendo la contestación taxativa: las prevenciones debían realizarse ${ }^{26}$. La polémica era interesante por el doble rasero demostrado por Navarra, que un mes antes había enviado una carta al consejo de Castilla para interceder, y reclamar, que las ciudades de Logroño, Calahorra y Alfaro no fueran obligadas a contribuir económicamente a la composición de milicias, para que así siguieran contribuyendo con sus milicias para defender Pamplona, contradiciendo su propia argumentación ${ }^{27}$.

La movilización fue corta. A comienzos de junio el virrey licenció a todos al desvanecerse el miedo a una invasión, aunque debían estar listos para volver a la primera orden ${ }^{28}$. Los cuatro tercios estuvieron convocados durante 23-24 días — dependiendo de la unidad-, siendo sus socorros pagados mediante los 3.000 doblones extraordinarios enviados a Navarra. Los cuatro tercios — de Francisco

23 CCE, 10 de agosto de 1674. AGS, E, leg. 2699. Parma al rey, Pamplona, 7 de junio, 2 y 30 de agosto de 1674. Diputación al rey, Pamplona, 2 de agosto de 1674. AGS, GA, leg. 2319. Rey al Virrey, Madrid, 23 de julio y 20 de agosto de 1674. AGS, GA, libro 331 f. 8 y 14v. Diputación a Parma, Pamplona, 2 de junio de 1674. Respuesta de Parma, Pamplona, 10 de junio de 1674. Como los navarros deben servir en la hueste del rey, s/f. ARGN, Guerra, leg. 5 n ${ }^{\circ} 54$. Mariana a Navarra, Madrid, 18 de julio de 1674. Coloma a Navarra, Madrid, 25 de julio de 1674. Orden Real, Madrid, 23 de julio de 1674. ARGN, Guerra, leg. 5 n 55.

24 Diputación a Mariana, Pamplona, 24 de julio y 2 de agosto de 1674. ARGN, Guerra, leg. 5 n 55.

25 CCG, 11 y 29 de abril de 1689. AGS, GA, leg. 2791. Cuentas de Juan Echalar, 1689. AGS, Contaduría Mayor de Cuentas $3^{a}$ época (en adelante CMC3), leg. 2778 f.8.

26 Memoriales de la diputación al Virrey, Pamplona, 23, 24 y 26 de abril de 1689. Respuestas del virrey, Pamplona, 23, 24 y 26 de abril de 1689. Rey a Navarra, Madrid, 6 de mayo de 1689. AGRN, Guerra, leg. 5 n 39.

27 Navarra al consejo de Castilla, Pamplona, 9 de marzo de 1689. AGRN, Guerra, leg. 5 no 37.

28 Virrey a la diputación, Pamplona, 3 de junio de 1689. Respuesta de la diputación, Pamplona, 3 de junio de 1689. AGRN, Guerra, leg. 5 n 41. 
Alonso de Herrera, Joseph de Elío, el marqués de Santacara y el Conde de Ablitas - reunieron, entre el 15 de mayo al 7 de junio — según lo pagado_, 4.047 soldados y 290 oficiales $^{29}$.

En otros casos, las quejas vinieron después. Durante la Guerra de Luxemburgo (1683-1684), se llevó a cabo de una nueva movilización cuando a mediados de marzo los franceses ocuparon la ermita de San Salvador de Ibañeta, para después retirarse a sus posiciones en los montes Alduides, ya que su única intención era reconocer las defensas. La acción generó miedo, ya que la ermita se encontraba en una posición clave, a tiro de mosquete de Roncesvalles. Además, para dar más fundamento a los miedos, se creía que los franceses reunían 13.000 efectivos - la mayoría milicianos-. Se tomaron medidas tanto para movilizar a los naturales, y se envió dinero y soldados desde otras partes. Sin embargo, la movilización sería breve, ya que pronto se vio que las tropas francesas se trasladaban a Cataluña ${ }^{30}$. Se reunieron dos de los cuatro tercios del reino, y sus hombres se mantuvieron en el puerto de Burguete y Pamplona entre el 21 de abril y el 11-25 de mayo, fechas en las que progresivamente volvieron a sus hogares ${ }^{31}$. La experiencia no fue exitosa, viéndose su movilización impedida por el mal tiempo y la falta de dinero ${ }^{32}$. Todo ello con un coste elevado, ya que solo el mantenimiento de los oficiales de los dos tercios convocados — de Joseph de Elío y Juan Cruzat y Góngora - ascendía a 22.410 reales de plata mensuales ${ }^{33}$.

Esa última cuestión nos introduce al coste económico. La movilización de los cuatro tercios en 1682 duró unas pocas semanas, hasta que comenzaron a llegar refuerzos a Pamplona desde otras partes. Los cuatro tercios se movilizaron durante el mes de febrero, llegando a tener 4.216 efectivos entre oficiales y soldados. $\mathrm{Su}$ socorro mensual era demasiado elevado al ser el mismo que el de un profesional y ascender a 143.112 reales de plata, el 62\% de lo pagado. De hecho, siempre que eran movilizados los tercios de milicias cobraron su socorro, algo que no podían decir los profesionales, ya que sus pagas se dilataban varios meses. De tal manera que en febrero de 1682 la guarnición ordinaria de Pamplona — 411 hombres_-, solo cobraba dos terceras partes del sueldo ${ }^{34}$. El coste corría a cargo del rey, por lo que la propia

29 Cuentas de Juan de Echalar, 1689-95. AGS, CMC3, legs. 1393 y 2663.

30 Velandia al reino, Pamplona, 21 de marzo de 1684. Navarra al rey, Pamplona, 21 de marzo de 1684. Velandia al rey, Pamplona, 22 de marzo de 1684. AGRN, Guerra, leg. 5, $\mathrm{n}^{\circ} 18$. Navarra a Medinaceli, Pamplona, 21 de marzo de 1684. Respuesta de Medinaceli, Madrid, 29 de marzo de 1684. AGRN, Guerra, leg. $5 \mathrm{n}^{\circ}$ 19. Por parte francesa, las menciones son escasas al tratarse de una acción menor (Drévillon, 2015, pp. 31-32).

31 Cuentas de Juan de Echalar, 1681-86. AGS, CMC3, leg. 1325.

32 Navarra a Velandia, Pamplona, 27 de marzo de 1684. Velandia a Navarra, Pamplona, 28 de marzo de 1684. AGRN, Guerra, leg. 5 nº 22.

33 CCG, 5 de abril de 1684. AGS, GA, leg. 2608.

34 CCG, 27 de febrero de 1682. Relación de la gente, 19 de febrero de 1682. Reglamentos sobre la defensa de los valles, 18 de enero de 1682. AGS, GA, leg. 2543. 
monarquía usó este recurso con moderación, y solo en momentos puntuales, ya fuera por el gasto, como por «no incomodar al país» ${ }^{35}$.

Podemos analizar las seis ocasiones en la que se realizó el llamamiento de los tercios durante el reinado de Carlos II, si bien en dos de ellas éste no se terminó produciendo. En 1674 se anuló al no necesitarse, pero en 1697 los motivos fueron diferentes. Durante ese verano, debido al asedio de Barcelona, se sacaron de Navarra todas las unidades profesionales, además de un tercio de las milicias extremeñas que había llegado recientemente. La situación era desesperada, por lo que también se pretendía enviar a Cataluña a los cuatro tercios, si bien pronto se rebajó la petición a 500 hombres. Aunque los profesionales y milicianos foráneos fueron despachados a Cataluña, no se pudo movilizar a los navarros, tanto porque el encargado era el marqués de Conflans, nuevo en el cargo, como por el hecho de que las milicias deberían salir de Navarra, algo que no había ocurrido desde $1641^{36}$.

La Diputación siempre se mostró muy combativa ante cualquier movilización. En 1684 daría un paso más allá, cuando a través de un memorial intentó extinguir los tercios. Sus quejas se centraban en el fuero militar y el nombramiento de los oficiales, razones que escondían el fondo de la cuestión: la Diputación no los controlaba. Por un lado, las autoridades civiles se quejaban de que todo el que tenía fuero militar pretendía estar exento de los repartos concejiles. La Diputación intentó que los militares casados y con hacienda sí contribuyesen a los repartos de los pueblos y los impuestos reales, cuestión que contravenía la esencia del fuero militar. Finalmente, la Diputación consiguió su propósito, ya que, aunque los militares profesionales quedaron exceptuados, los oficiales en los cuatro tercios - que pocas veces estaban movilizados-, fueron obligados a contribuir en $1696^{37}$. En el memorial, se señalaba a los oficiales, ya que - aunque muchos eran caballeros conocidos, y de primera estimación-, había otros que habían tenido oficios mecánicos —especialmente alféreces y sargentos—-, algo que a su juicio era indigno, al no merecer sus grados, ya que pretendía que todos fueran hijosdalgo. En su opinión, muchos solicitaban esos puestos por gozar de fuero, y cometían desordenes ya que no se seguía la costumbre antigua de que los oficiales fueran elegidos por las ciudades y villas. Por ello, era partidario de suprimirlos, ya que, a su juicio, con el llamamiento amparado en los fueros bastaba para defender el reino. Esto no fue aceptado, ya que en Madrid se consideraba que los tercios eran un instrumento útil para defender Navarra ${ }^{38}$.

35 CCG, 27 de febrero de 1682. AGS, GA, leg. 2543.

36 CCG, 5 de julio de 1697. AGS, GA, leg. 3043. Conflans al rey, Pamplona, 18 de julio de 1697. Muestra pasada..., Pamplona, 18 de julio de 1697. AGS, GA, leg. 3067. Conflans al rey, Pamplona, 14 de julio de 1697. AGS, E, leg. 4182.

37 Memorial de Estella, 25 de junio de 1696. Instrucción de la Diputación del Reino, Pamplona, 21 de julio de 1696. ARGN, Guerra, leg. 5 nº 49 y 50.

38 Memorial del reino, Pamplona, 24 de abril de 1684. AGRN, Guerra, leg. 5 nº 29. CCG, 14 de agosto de 1684. AGS, GA, leg. 2610. 
El otro problema de fondo era la elección de los oficiales, pues la Diputación quería obtener esa prerrogativa. Los maestres de campo solían ser nobles navarros, que se beneficiaban de los nombramientos, aunque no siempre tuvieran mucha experiencia militar. De optar a un nombramiento fuera de Navarra lo hubieran tenido bastante difícil, pero formaban parte de un selecto número de familias de raigambre militar que coparon gran parte de los nombramientos - con apellidos como Ibero, Cruzat, Beaumont, Elío, Gorraiz, Ongay o Ezpeleta-, entre los que había regidores de Pamplona, dueños de palacios, o miembros con voto en las Cortes ${ }^{39}$, pero también nuevos titulados, como el conde de Ablitas o los marqueses de Santacara y Góngo$\mathrm{ra}^{40}$. Esa relación directa entre el rey y los principales mandos conllevó a que también existieran formas paralelas a la hora de movilizar — mediante los oficiales de los tercios-, empleadas para eludir la gestión de la Diputación.

En 1695 se pidió la movilización, que volvió a contar con la oposición del reino. No parece casual que esta fuera ejecutada por el maestre de campo Tomás de Elío, al que el virrey había apoyado ante el consejo de Guerra para suceder a su padre al mando de uno de los tercios ${ }^{41}$. El motivo era la única acción militar de importancia que hubo durante toda la Guerra de los Nueve Años en Navarra, cuando el virrey marqués de Valero - con 2.000 infantes y las compañías de dragones que servían en Navarra - cruzó los Pirineos. La operación duro un par de días, y fue un éxito, al demolerse cerca de 300 casas y cabañas para el ganado en los montes Alduides ${ }^{42}$. Al saber que las milicias se reunían, la Diputación escribió por dos veces al virrey instándole a que sobreseyese las órdenes, indicando que no se podía hacer guerra, paz o tregua sin el consentimiento de los Tres Estados del reino. La movilización planeada, según la Diputación, conllevaría el menoscabo del reino, con argumentos ya empleados en otras ocasiones. Las diversas contestaciones del virrey se realizaron sobre la marcha hacia la frontera. De manera muy escueta, respondió que el rey ya había considerado esos problemas, y que él, como servidor real, solo miraba en beneficio de la causa pública. En total se juntaron 1.000 hombres, cuya misión fue cubrir

39 Diez títulos de maestres de campo de los tercios, 27 de febrero de 1662, 19 de mayo y 14 de septiembre de 1668, 9 de diciembre de 1671, 25 de noviembre de 1672, 9 de abril de 1674, 18 de septiembre de 1681 (2), 31 de diciembre de 1686, 24 de noviembre de 1688. AGS, GA, libros 276, $309,319,322,361,393$ y 405.

40 Títulos de marqueses de Santacara y de Góngora, Madrid, 28 de junio de 1693 y 7 de marzo de 1695. AGS, Cámara de Castilla (en adelante CC), Lib. Relación 41 f. 195 y 272v.

41 Valero al Rey, Pamplona, 1 de abril de 1693. Archivo Histórico de la Nobleza (en adelante AHNobleza), Osuna, C.315 D. 710. Junta de Tenientes Generales, 25 de enero de 1694. AGS, GA, leg. 2950.

42 Copia de carta, escrita por el Excelentísimo señor marqués de Valero, Virrey, y Capitán General del Reyno de Navarra, al Rey N. S. en 17 de mayo de 1695 (Impresa), Zaragoza, Jaime Margallón, 1695. Valero a González Botello y a Solar, Pamplona, 2 de junio y 14 de julio de 1695 . Larrea a Valero, Aranjuez, 24 de mayo de 1695. Orden Real, Madrid, 1 de junio de 1695. AHNobleza, Osuna, C.315 D.547, 768, 770 y 773. 
los pasos fronterizos mientras los profesionales realizaban la expedición punitiva en suelo francés. La movilización no duró ni una semana, y en Madrid fue justificada afirmando que era para la seguridad del reino ${ }^{43}$.

Generalmente, los tercios fueron llamados al iniciarse cada enfrentamiento con Francia — como en 1684 o 1689 - durante la primera campaña, y solo durante un mes. En esto tenía mucho que ver que los franceses pasaban muestra a sus milicias, ya que ese tipo de llamamientos eran una demostración de fuerza ${ }^{44}$. En 1682 también se movilizaron los tercios, y aunque en esa ocasión no había guerra, los movimientos franceses motivaron el llamamiento. Otra excepción será la movilización de 1695, motivada por una acción ofensiva en territorio francés, de apenas una semana.

Tabla 1. La movilización efectiva de los cuatro tercios de milicias del reino de Navarra (1665-1700)

\begin{tabular}{|c|c|c|}
\hline Año & Número de tropas (oficiales y soldados) & Días movilizados \\
\hline 1682 & 4.216 & 30 \\
\hline 1684 & 2.000 (después 800 ) & $20-34$ (retiro gradual) \\
\hline 1689 & 4.337 & $23-24$ \\
\hline 1695 & 1.000 & 7 \\
\hline
\end{tabular}

Fuente: AGS, GA, legs. 2302, 2543, 2608, 2611, 2791 y 3043. AGS, E, legs. 2699 y 4182. AGS, CMC3, legs. 1325, 1393, 2663 y 2778. AHNobleza, Osuna, C.315. AGRN, Guerra, legs. 4 y 5.

\section{Las milicias fronterizas}

Los habitantes de los valles fronterizos no tenían la obligación de servir en los tercios de milicias, pero debían defender sus hogares, algo que también justificaba alguno de sus privilegios, como el de hidalguía (Idoate, 1981, p. 19). Su número era variable, ya que dependía de la población en edad militar, pero para algunas fechas tenemos datos bastante precisos. En 1682 se redactaron diversos reglamentos, dándose instrucciones a los habitantes para que supieran los puestos y lugares que debían defender, indicándoles la estrategia a seguir para aprovechar la orografía y defender los pasos. Estas instrucciones nos muestran los milicianos

43 Memoriales (3) de la diputación al virrey, Pamplona, 14 y 19 de mayo de 1695; con respuestas adjuntas. Navarra al Rey, Pamplona, 14 de mayo de 1695. Rey al reino, Aranjuez, 25 de mayo de 1695. AGRN, Guerra, leg. 5 n ${ }^{\circ}$ 48. Valero a González Botello y a Solar, Pamplona, 2 de junio y 14 de julio de 1695. Larrea a Valero, Aranjuez, 24 de mayo de 1695. Orden Real, Madrid, 1 de junio de 1695. AHNobleza, Osuna, C.315 D.547, 768, 770 y 773.

44 Navarra al Rey, Pamplona, 8 de abril de 1684. Orden Real, Madrid, 29 de abril de 1684. AGRN, Guerra, leg. $5 \mathrm{n}^{\circ}$ 25. Miranda al rey, Pamplona, 11 de abril de 1684. Miranda al reino, Pamplona, 11 de abril de 1684 y Burguete, 16 de abril de 1684. AGRN, Guerra, leg. 5 n 26. Rey al reino, Madrid, 9 de mayo de 1684. AGRN, Guerra, leg. 5 n 27. CCG, 19 de julio de 1684. AGS, GA, leg. 2611. 
que había en Vera (670), Maya (245), Baztán (900), Burguete (1.043), Roncal (501) y Salazar $(441)^{45}$.

Los tres puertos de montaña principales solían ser custodiados por un pequeño grupo de soldados desplazados desde Pamplona, que servían por turnos a cargo de los gobernadores de los puertos, nombrados por los capitanes generales ${ }^{46}$. Cuando se temía cualquier ataque, todos los hombres hábiles de entre 14 y 60 años podían ser movilizados. En 1684 las milicias de los valles se movilizaron durante los días 2127 de marzo para cerrar los pasos de Roncesvalles y Burguete. Los primeros días se movilizaron 800 paisanos, aunque al cuarto día se ordenó que solo quedarán 200 —al reconocerse que por los fueros los tres primeros días debían hacerlo sin gasto-, si bien después fue necesario mantener a los demás a cargo del reino ${ }^{47}$. Esta clase de servicios generaban quejas por criterios económicos. Muchos hombres no deseaban abandonar sus quehaceres y los valles se quejaban. Desde finales de abril de 1689 los gobernadores de los pasos avisaron de los movimientos franceses. Los dispositivos defensivos suponían el establecimiento de algunos guardias en los altos aportados por los pueblos de la zona, pero algunos valles no acudieron, como el valle de Arce. Sus paisanos se negaban a acudir porque querían recibir un sueldo, ya que en 1684 estuvieron movilizados en los pasos por 40 días sin recibir socorro. La respuesta del virrey se ciñó a representar que solo se pagaba a los hombres asentados en los libros reales, y que los paisanos acudían a su propia defensa siguiendo las leyes ${ }^{48}$. No es de extrañar que en esa ocasión se despacharan profesionales escogidos de los tercios desplegados en Pamplona al puerto de Burguete. Los 2.000 milicianos de los valles para su defensa, solo se convocarían en caso de necesidad, limitándose — a juicio del virrey - a pagarles las municiones ${ }^{49}$. Algúnos pueblos, para evitar participar, sugirieron contribuir con dinero, o con soldados para los tercios de milicias, debido a que cuando participaban en las guardias de los pasos no recibían estipendio ${ }^{50}$.

45 CCG, 27 de febrero de 1682. Reglamentos sobre la defensa de los valles, 18 de enero de 1682. AGS, GA, leg. 2543.

46 Rey a Bournonvile, Madrid, 8 de octubre de 1686. AGS, GA, libro 394 f. 106v.

47 Íbero al rey, Pamplona, 23 de abril de 1684. AGRN, Guerra, leg. 5 nº 20. Velandia a los Tres Estados del reino, Pamplona, 24 de marzo de 1684. Respuesta al virrey, Pamplona, 24 de marzo de 1684. AGRN, Guerra, leg. 5 nº 21.

48 Domingo Cristóbal al virrey, Burguete, 23 de abril de 1689. Memorial del valle de Arce, 25 de abril de 1689. Virrey al valle, Pamplona, 26de abril de 1689. AGRN, Guerra, leg. 5 no 40.

49 CCG, 11 y 29 de abril de 1689. AGS, GA, leg. 2791. Cuentas de Juan Echalar, 1689. AGS, CMC3, leg. $2778 \mathrm{f} .8$.

50 Memorial de la villa de Aoiz, s/f. Solar a Valero, Madrid, 16 de febrero de 1697. AHNobleza, Osuna, C.315 D.60 y 398. 


\section{Las compañías de caballería}

En tiempos medievales había existido una milicia hidalga, los remisionados, que podían ser de a pie y de a caballo. Se trataba de hidalgos que a cambio de la exención del pago de cuarteles y alcabalas acudían a la defensa del reino. La institución, aunque en desuso, pervivió. La compañía de infantería quedó extinguida durante la primera mitad del siglo XVII, pero la de caballos perduraría hasta el siglo XVIII. Sus jinetes no cobraban sueldo debido a las exenciones fiscales, pero tenían la obligación de presentarse a los alardes anuales con su equipo y caballos (Idoate, 1981, pp. 2628). A la altura de 1630, para intentar movilizar a los navarros, se dio el cargo a Gerónimo Ayanz, caballerizo de la reina y del consejo de hacienda. En ese momento se esperaba que la compañía reuniera 50 jinetes, que ya habían cambiado sus lanzas por arcabuces. A su muerte, le sucedió su sobrino, teniendo el capitán 25.000 maravedíes anuales de sueldo, además de otros 25.000 para el teniente y el trompeta ${ }^{51}$. La familia, gracias al favor real, conseguiría el título de condes de Guenduláin $(1663)^{52}$.

Eran tropas sobre el papel, pero nunca se movilizaban. En 1691 se esperaba su reactivación, siendo necesario que se pasara una muestra rigurosa ante la suposición de que la compañía no tenía ni hombres ni caballos ${ }^{53}$. Nada se consiguió, y en 1694, a la muerte del conde de Guenduláin, el consejo de Guerra vio la oportunidad de reactivar la compañía, aprovechando el interés de la nobleza navarra. El virrey terminó concediéndosela al marqués de Campo Nuevo, recientemente titulado ${ }^{54}$. La nueva concesión implicaba que la compañía se restableciese bajo su pie antiguo ${ }^{55}$.

En distintos informes a lo largo del siglo XVII se habla de otra de las compañías de caballería de naturales, la del condestable de Navarra, que tras la conquista se había convertido en una más de las Guardas de Castilla (Quatrefages, 1996, pp. 295296). En 1676 se intentó que la compañía fuera efectiva. Sobre el papel disponía de 60 hombres, pero la mayoría no tenían caballos propios, siendo necesario conseguir monturas, y aumentar su dotación hasta los 100 jinetes $^{56}$. En 1691 se volvía a intentar su reactivación ${ }^{57}$. El problema de fondo era la manifiesta decadencia de las Guardas

51 Títulos de capitán de los remisionados, Madrid, 19 de agosto de 1630; y 15 de octubre de 1659. AGS, GA, libros 157 f. 18; y 261 f. 211. CCG, 1 de agosto de 1635. Patente a Gerónimo de Ayanz, 19 de agosto de 1630. AGS, GA, leg. 1.120.

52 Título de conde de Guendulayn, 21 de septiembre de 1663. AGS, CC, Lib. Relación 37 f. 171v.

53 Rey a Villena, Madrid, 11 de julio de 1691. AHNobleza, Frías, C.60, D. 3.

54 Título de marqués de Campo Nuevo, 10 de enero de 1689. AGS, CC, Lib. Relación 40 f. 301.

55 Memorial para la obtención de la compañía, 9 de noviembre de 1694. AGS, GA, leg. 2969. Garcia Bustamante a Valero, Madrid, 24 de noviembre de 1694. Camponuevo a Valero, Viana, 8 de octubre de 1694. Valero al Rey, Pamplona, 21 de octubre de 1694. Cédula Real, Madrid, 19 de noviembre de 1694. AHNobleza, Osuna C.315, D. 573, 598, 599 y 600.

56 Rey a Parma, Madrid, 1 de mayo y 17 de julio de 1676. AGS, GA, libro 331 f. 150 y 175v.

57 Rey a Villena, Madrid, 11 de julio de 1691. AHNobleza, Frías, C.60, D. 3. 
de Castilla, que, aunque sobre el papel se mantenían alojadas en las tierras de los nobles que las dirigían, los intentos de reactivarlas no tuvieron éxito ${ }^{58}$. Ante la falta de caballería, en 1693 se formaron cuatro compañías de dragones para defender Navarra, que dispusieron de cerca de 200 efectivos reclutados en Madrid y La Rioja ${ }^{59}$.

\section{Los servicios de tropas aprobados por las Cortes}

Los apercibimientos generales darían paso a los cuatro tercios de milicia, pero el problema seguía siendo la interpretación de los fueros, sus limitaciones al servicio - geográficas y temporales - , así como el sistema de reclutamiento obligatorio. La salida de los navarros durante 1636 o 1638, aunque criticada, sería por pocas semanas y cerca de sus hogares. Las cosas cambiaron con el envío de los tercios de milicias a la frontera de Aragón en 1640. Desde entonces la Diputación fue más combativa. Las Cortes de 1642 redactaron un cambio normativo, y prohibieron a los virreyes publicar bandos, realizar repartimientos, o sacar a servir a los navarros fuera del reino sin consentimiento ${ }^{60}$. Con dicho cambio se formalizaba una nueva dinámica. Los servicios de tropas organizadas en tercios — reclutados y pagados por el reino-, se votaban en las Cortes, y servían por tiempo limitado, siguiendo el método pactista por el que otras regiones colaboraban con la defensa de la monarquía (Solano, 1987; Sanz, 1997; Espino, 2004 y 2007).

Desde 1642 a 1646 las Cortes aprobaron cinco servicios de tropas para servir en la frontera aragonesa. Esto coincidió con la presencia de Felipe IV en Aragón, cerca del frente, recordando la posibilidad que daban los fueros de que en caso de que el rey en persona convocase una hueste, se le podría servir por más días ${ }^{61}$. En total, los servicios ascendieron a 3.580 hombres por 4 meses - tiempo que estaban movilizados, pagados por el reino (Rodríguez Garraza, 2007, pp. 378-385) - , si bien la generosidad navarra se fue reduciendo, de los 1.300 hombres iniciales a los escasos 560 de $1646^{62}$. Desde entonces las concesiones se hicieron más difíciles. Durante la década de 1650 el consejo de Guerra chocó con la necesidad de convocar Cortes con cada servicio ${ }^{63}$. En 1652 la monarquía volvería a arrancar un servicio de 500 hombres pagados por tres meses, hasta finales de ese año, para asistir al asedio de Barcelona, una petición nada descabellada, ya que se sumaba a las contribuciones de tropas — por métodos obligatorios_ practicados en toda Castilla, y que ascendían a más

58 CCG, 19 de julio de 1669, 8 de febrero de 1682 y 23 de junio de 1693. AGS, GA, legs. 2195, 2543 y 2913.

59 Libranzas de pago, Pamplona, 29 de junio de 1693. AGS, CMC3, leg. 2744 f.14.

60 Novíssima recopilación ..., tomo I, pp. 149.

61 Fuero General de Navarra, Libro I, Título I, cap. V.

62 Condiciones del servicio, 1646. AGS, GA, leg. 1825.

63 Junta de Guerra de España, 15 de diciembre de 1650. AGS, GA, leg. 1748. 
de 11.000 hombres (Rodríguez Hernández, 2011, pp. 184-186). El servicio saldría de Navarra a pocos días de la rendición de Barcelona, y sin que el reino accediese a colaborar más tiempo, a pesar de las continuas peticiones ${ }^{64}$.

La monarquía intentó que el servicio se prorrogase, o que fuera periódico, aunque solo consiguió que a mediados de 1653 Navarra se comprometiese a servir con 500 hombres por 3 meses, sin bien de nuevo el servicio se ponía en marcha muy tarde, a comienzos de octubre. Tampoco se consiguió que el reino alargase el servicio otros 3 meses, o lo convirtiera en anual, a pesar de las facilidades ofrecidas ${ }^{65}$. En 1654 - a pesar de que se pidieron 1.000 hombres - , las Cortes solo acordaron la concesión de 20.000 ducados, pero sin contribuir en hombres. La recluta se realizó en Castilla, ante la reiterada negativa de enganchar a los fugitivos de la leva anterior. Se había descubierto que, en 1653, al llegar a Fraga había 220 hombres menos — casi la mitad-, por lo que la monarquía esperaba que los desertores fueran capturados ${ }^{66}$. En 1656 se intentó reclutar de nuevo, pensando sacar de cada una de las compañías de milicias entre 4 a 6 soldados. El problema, como indicaba el virrey, era que el «medio de sacar gente natural del reino es impracticable sin convocar cortes», y sin la colaboración de éstas lo único que se podía hacer era reclutar voluntarios, ya fueran naturales, forasteros o derrotados de otros ejércitos que estaban de paso ${ }^{67}$. Pasarían nueve años hasta el siguiente servicio, un tercio de 540 efectivos pagados por 6 meses en la Armada (Rodríguez y Díaz, 2018, pp. 265-275).

A finales de 1673, en vista del enfrentamiento con Francia, el consejo de Estado intentó — sin éxito - que Navarra aportara tropas para la campaña de 1674 retomando el sistema ${ }^{68}$. En los años siguientes se volvió a plantear la cuestión ante la inactividad de la frontera. Incluso en la planificación general de 1675 - que pretendía reunir 20.700 hombres en toda la península—, se esperaba que Navarra aportará tropas, sin establecer cupo ${ }^{69}$.

64 Junta de Guerra de España, 19 de noviembre de 1652. Condiciones del servicio, 1652. AGS, GA, leg. 1825. Junta de Guerra de España, 31 de diciembre de 1652. AGS, GA, leg. 1809. Patentes e instrucciones, 5 de octubre de 1652. AGS, GA, libro 225 f. 159. Relación de servicios de Francisco Gorraiz. Archivo General de Indias (en adelante AGI), Indiferente, leg. $125 \mathrm{n}^{\circ} 23$.

Junta de Guerra de España, 11 de febrero y 1 de junio de 1653. AGS, GA, leg. 1825. Relación de la gente que se levanta, Madrid, 24 de octubre de 1653. AGS, GA, leg. 1840. Rey a Escalona, 27 de noviembre y 27 de diciembre de 1652. Rey a Juan de Arce, 31 de mayo de 1653. Rey a Santiesteban, 14 de septiembre de 1653. Rey a Juan de Austria, 6 de diciembre de 1653. AGS, GA, libro 237 f. $61 \mathrm{v}, 65,108,134,149 \mathrm{v}$ y 198.

66 Junta de Guerra de España, 22 de mayo de 1654. AGS, GA, leg. 1846. Rey a Satiesteban, 6 de enero de 1654. Instrucciones para reclutar cuatro compañías en Castilla, 15 de mayo de 1654. AGS, $G A$, libro 243 f. 60v y 91v. Rey a Satiesteban, 6 de mayo y 16 de noviembre de 1654 . Rey a Juan de Austria, 25 de mayo de 1654. AGS, GA, libro 245 f. 3, 9 y 53. Satiesteban, 1 de marzo de 1656. AGS, GA, libro 243 f. 185v.

68 CCE, 15 de noviembre de 1673. AGS, E, leg. 2697.

69 Ontiveros al rey, Madrid, 31 de agosto de 1675. CCG, 6 de septiembre de 1675. AGS, GA, leg. 2338. 
En 1677 las circunstancias cambiaron. El virrey convocó Cortes, reuniéndose éstas en abril ${ }^{70}$. En los primeros momentos las intervenciones se centraron en enumerar agravios y contrafueros, algo habitual. Pero después, el virrey consiguió un acuerdo. Como argumentos Fuensalida indicaba la excepcionalidad de la medida, los apuros de la hacienda, y los recientes «aprietos» - especialmente en Flandes y Sicilia- Con ello esperaba la contribución «en esta ocasión forzosa». Además de la necesidad de renovar los servicios económicos de cuarteles y alcabalas, se pedía un servicio en tropas de uno o dos tercios de infantería para servir en Cataluña ${ }^{71}$. Las bazas del virrey eran la necesidad de la gracia real para que los naturales obtuvieran premios y honores, y el ánimo del reino por mantener sus privilegios y fueros ${ }^{72}$. A pesar de la premura, las Cortes pronto discutieron y aceptaron el servicio, que sería muy parecido al de las últimas aportaciones —el tercio movilizado en 1662-, si bien levantando más hombres. Rápidamente se estudiaron los arbitrios y condiciones, no tardando en llegar el consenso ${ }^{73}$.

La aportación consistiría en movilizar un tercio de 600 infantes para Cataluña, sin contar con los oficiales, en 9 compañías. Todo ello pagado por 6 meses, a razón de un real de plata al día a cada soldado y a los oficiales $2 / 3$ de su paga al mes - debiendo suministrar el rey el pan de munición en el ejército-, suministrando el reino el vestuario y las armas. Los hombres debían ser españoles, y los municipios los movilizarían vía repartimiento a través de sus regidores, prohibiéndose los fraudes y que se beneficiara a unos frente a otros. Los elegidos debían ser naturales de los mismos lugares por los que servían, o al menos debían haber residido en ellos por un año. Los designados y sus hijos serían excluidos de futuros reclutamientos. Para evitar el desconsuelo de las mujeres e hijos de los soldados se prohibía que sus familias fueran molestadas por acreedores, o causas civiles o criminales durante el tiempo que estuvieran sirviendo ${ }^{74}$.

Para conseguir el dinero para el reclutamiento, socorro de las tropas - los soldados cobrarían dos reales de plata al día-, y conducción hasta el punto de entrega, los pueblos podrían recibir facultades extraordinarias para sufragar el gasto, esta-

$70 \quad$ Rey a Fuensalida, 17 de marzo de 1677. AGS, GA, libro 331 f. 262 v.

71 Virrey a las Cortes, Pamplona, 6 de abril de 1676. ARGN, Guerra, leg. 4 n 60 . Mariana a Navarra, Madrid, 9 de abril de 1677. AGS, GA, libro 331 f. 277.

72 Fuensalida al rey, Pamplona, 30 de marzo y 5 de abril de 1677. CCG, 5 y 21 de abril de 1677. AGS, GA, leg. 2375. Fuensalida al rey, Pamplona, 25 y 30 de marzo de 1677. AGS, GA, leg. 2399. Fuensalida al rey, Pamplona, 30 de marzo de 1677. AGS, GA, leg. 2405. Fuensalida al rey, Pamplona, 25 de marzo y 9 de abril de 1677. AGS, GA, leg. 2405. Rey a Fuensalida, 9 de abril de 1677. AGS, GA, libro 331 f. 276v.

73 Fuensalida al reino, Pamplona, 11 de abril de 1676. Arbitrios para la leva, s/f. ARGN, Guerra, leg. $4 \mathrm{n}^{\circ}$ 61. Condiciones aprobadas, 1 de mayo de 1677. (varias copias, incluso una impresa) ARGN, Guerra, leg. 4 n 62 y 63.

74 Rey a Fuensalida, 1 de mayo de 1677. Condiciones del servicio, Pamplona, 1de mayo de 1677. AGS, $G A$, libro 331 f. 286 y 293 v. 
bleciéndose que los mercaderes - ya fueran locales o extranjeros - no quedaran exentos, al ser de los sectores más pudientes. Por otro lado, se debía actuar con total igualdad, algo que posteriormente motivaría quejas ${ }^{75}$. El dinero sobrante de las bajas - ya fueran por deserción o muerte-, se retendría por el pagador ${ }^{76}$.

Una vez hubiera terminado el alistamiento, la entrega de las tropas se produciría en la raya del reino, siendo recibidos en ese punto por los oficiales del sueldo e inscritos oficialmente en los libros reales. Si los hombres desertaban desde entonces, no se debían cubrir las bajas, aunque los desertores serían perseguidos en cumplimiento de las ordenanzas militares, tomándose medidas contra los que los encubriesen. Si la fuga ocurría antes de la entrega de las tropas, los desertores debían pagar una multa de 24 ducados, y serían obligados a servir en la frontera de Cataluña, u otro presidio, por un año. El servicio era exclusivamente para el ejército de Cataluña por 6 meses — que empezaban a correr desde la entrega de los hombres - , prohibiéndose que las tropas sirvieran en otra parte. Pasado ese tiempo, la unidad se retiraría sin que los hombres incurrieran en la pena de deserción, concediéndose a los oficiales el grado de reformados, pudiendo éstos continuar en el ejército si lo deseaban.

Las condiciones fueron confirmadas por Carlos II desde Zaragoza, acelerándose los preparativos y ajustándose los repartos entre las ciudades, villas, valles y céndeas. Durante esas semanas se terminaron de ajustar algunas exenciones para que algunos sectores no contribuyeran con hombres o dinero - como los jesuitas o los fabricantes de pólvora-, ajustándose que la unidad debía estar lista el 20 de mayo en Sangüesa. Poco después se producirían cambios, ya que de manera sucesiva se sustituyó la plaza de entrega, primero a Urroz y después a Cortes - en el Ebro_-, debido a que el tercio pasaría por Zaragoza, estableciéndose como nueva fecha el 22 de mayo. Otra modificación sería que el rey entregaría las armas a los soldados a cargo de las fábricas reales de Guipúzcoa ${ }^{77}$. También se entregaron a los oficiales picas y pertrechos como pólvora y cuerda de los almacenes de Pamplona, además de armas defensivas - como golas, petos, espaldares y morriones - , para que tuvieran un aspecto más adecuado, al ser los géneros de calidad. Aunque eso último no se había estilado en otras ocasiones,

75 Memorial de los comerciantes, s/f. ARGN, Guerra, leg. $5 \mathrm{n}^{\circ} 30$.

76 Condiciones aprobadas por su majestad, 14 de abril de 1677. Para ver en el consejo, Madrid, 20 de abril de 1677. AGS, GA, leg. 2399.

77 Rey a Navarra, Zaragoza, 1 y 5 de mayo de 1677. Fuensalida a la diputación, Pamplona, 8 y 9 de abril de 1676. Diputación al virrey, Pamplona, 10 de mayo de 1677. ARGN, Guerra, leg. 4 n 61. Navarra al virrey, Pamplona, 11 y 12 de mayo de 1677. Fuensalida a Navarra, Pamplona, 12, 18 y 21 de mayo de 1677. ARGN, Guerra, leg. 4 n 65. Rey a Fuensalida, 1 de mayo de 1677. AGS, $G A$, libro 331 f. 286 . Fuensalida al rey, Pamplona, 15 de abril y 6 de mayo de 1677 . Urries al rey, Zaragoza, 11 de mayo de 1677. Pedro de Aragón al rey, Madrid, 27 de abril de 1677. Fernández al rey, Madrid, 27 de abril de 1677. AGS, GA, leg. 2399. 
se consideraba necesario ya que las tropas se pondrían en presencia del rey a su paso por Zaragoza ${ }^{78}$.

Todas las ciudades, villas y valles sirvieron según su población en el reparto de los 600 hombres, realizándose un prorrateo proporcional de un soldado por cada 51 vecinos y medio, aportando los lugares más pequeños exclusivamente dinero ${ }^{79}$. Las comunidades cumplieron con celeridad, y la unidad pudo marchar el 25 de mayo. El día antes se repartieron los soldados entre las compañías, que fueron equipadas de manera idéntica. La compañía del maestre de campo disponía de más hombres -72-, mientras que el resto estaban formadas por 66 . Todos recibieron un vestido de munición compuesto por hungarina de paño, chupa, calzón, camisa, corbata, sombrero blanco, medias encarnadas y zapatos blancos. Aunque no se indicaba el color del uniforme, podemos presuponer que era de color crudo de la lana, estando todo rematado con cintas encarnadas - como las medias-, el color característico de las fuerzas españolas. Todos los hombres llevaban como equipo una espada, con su tahalí, además de arcabuz, mosquete o pica. El reparto de las armas era a partes iguales entre las tres. Los mosqueteros llevaban además horquillas, frascos y frasquillos para la pólvora, con sus cordones, además de bandoleras. Los arcabuceros lo mismo, aunque sin horquillas. Los piqueros no llevaban otra cosa que la pica, ya que no disponían de equipamientos defensivos de metal ${ }^{80}$.

Durante el mes de mayo se consiguió aumentar el servicio con la incorporación de la décima compañía, formada íntegramente por la villa de Fitero, que aportó 60 infantes, más los oficiales, en las mismas condiciones. La compañía era un servicio de la villa como indulto de una causa criminal, ya que en 1675 habían protagonizado un motín - con el posterior asalto y saqueo al conocido monasterio-, debido a una vieja pugna jurisdiccional (Ostolaza, 2000, pp. 593-595). La villa debía reunir la compañía, algo que no la liberaba de cumplir con su cupo de 5 soldados al servicio general, por lo que su aportación era elevada, al ser una villa que tendría — según los repartos - 300 vecinos. El tercio pudo marchar el 25 de mayo con 660 soldados más oficiales, aunque antes el rey se debió comprometer a pagar durante las marchas por Aragón medio real más de plata, para que así los hombres estuvieran mejor asistidos — ya que durante el tránsito no se les podría proporcionar el pan de munición-, corriendo a cargo de la monarquía el pago de los comisarios de la Corona de Aragón y otros gastos menores ${ }^{81}$.

78 Pedro de Aragón al rey, Madrid, 29 de abril de 1677. AGS, GA, leg. 2393. CCG, 22 de noviembre de 1677. AGS, GA, leg. 2376. Rey a Lope de Tordoya, Madrid, 24 de octubre de 1677. Decreto real, Pamplona, 18 de mayo de 1677. AGS, GA, leg. 2404. Repartimiento de los 600 hombres, s/f. ARGN, Guerra, leg. 4 n $^{\circ} 64$.

80 Recibos del material entregado, Cortes, 24 de mayo de 1677. ARGN, Guerra, leg. 4 nº 78.

81 Fuensalida al rey, Tudela, 26 de mayo de 1677. AGS, GA, leg. 2399. Fuensalida al rey, Tudela, 26 de mayo de 1677 (dos de la misma fecha). AGS, GA, leg. 2404. Instrucciones a los comisarios del 
El reino se encargaba de elegir a los oficiales, gracias a las patentes en blanco —firmadas por el monarca — y los suplimientos — que exceptuaban a los elegidos de cumplir las ordenanzas, y especialmente con el tiempo de servicio requerido-, tanto para los oficiales como para sus subalternos ${ }^{82}$. En aras de elegir a los candidatos, la Diputación fue recibiendo continuas peticiones de los interesados en convertirse en oficiales, para después elegir a los que consideraba más idóneos. Peticiones que no siempre iban acompañadas por la pertinente relación de servicios justificada por las autoridades militares, como se anotaba en los márgenes de los escritos presentados ${ }^{83}$. Su análisis - junto con diferente información de los fondos del consejo de Guerra-, nos permite vislumbrar unas pautas definidas del perfil de los oficiales elegidos.

Más allá de ser naturales del reino, podemos ver patrones que casi todos los elegidos compartían. Una parte importante de los demandantes eran dueños - o herederos - de palacios, y la mayoría formaban parte de un selecto grupo de familias vinculadas al brazo militar de las Cortes. Sujetos que, en contraposición, mayoritariamente no disponían de relevantes servicios propios - tres de ellos no habían servido nunca, y otros cuatro menos de 5 años-, pero que formaban parte de familias que se habían distinguido en el servicio real por al menos tres generaciones. Incluso algunas como los Cruzat podían alegar servicios de hacía más de un siglo, al participar sus antecesores en las campañas del duque de Alba, la rebelión morisca o en la propia conquista de Navarra en tiempos de Fernando el Católico ${ }^{84}$. Es decir, respaldaban sus reivindicaciones más en los servicios pasados que en los propios. Respecto a la veteranía y años de servicio — sobre los casos que fueron elegidos y conocemos-, solo dos sujetos cumplían los requisitos marcados por las ordenanzas militares para acceder al puesto que obtuvieron - frente a cuatro que no-, y curiosamente el militar más veterano que pretendía alcanzar un puesto — con 18 años de servicio a sus espaldas - no lo consiguió ${ }^{85}$.

Dentro de la plana mayor de la unidad la mitad de los elegidos cumplía los requisitos. El sargento mayor - Fausto Cruzat y Góngora - solo atestiguaba haber servido dos años y 10 meses en la infantería de la Armada - al entrar a servir como entretenido en el tercio de Bernardo Lizarazu, formado en 1662, del anterior servicio navarro (Rodríguez y Díaz, 2018, pp. 265-275)—, si bien hacía 4 años que había

tercio, 30 de junio de 1677. AGS, GA, libro 345 f. 7v. Instrucciones a los comisarios de Aragón, 1 de mayo de 1677. Rey a Parma, 25 de abril y 18 de mayo de 1677. AGS, GA, libro 331 f. 287 , 290v y 292v. Memorial de Joseph Abdasolo, Pamplona 17 de mayo de 1677. ARGN, Guerra, leg. $4 \mathrm{n}^{\mathrm{o}} 77$. abril de 1677. AGS, GA, leg. 2399.

83 Memoriales fechados del 12-13 de mayo: ARGN, Guerra, leg. 4 nº 66-76.

84 Relación de servicios de Juan Cruzat, 1696. AGS, GA, SM, leg. 40 f. 58.

85 Memorial de Joseph de Berves, Pamplona, 12 de mayo de 1677. ARGN, Guerra, leg. 4 nº 67. 
abandonado el servicio activo ${ }^{86}$. Se insertaba en una familia de gran tradición militar, y su hermano Juan se convertiría en uno de los militares navarros más laureados del periodo, al ser sargento general de batalla ${ }^{87}$. Fausto Cruzat, tras dedicarse por un tiempo al comercio, se convertiría a finales de siglo en gobernador de las Filipinas (Herrera, 2015). En cambio, el maestre de campo — Lorenzo Ripalda-, no solo venía de una familia con una impresionante tradición militar a sus espaldas ${ }^{88}$ — su padre había servido durante más de 28 años, y de sus seis hijos varones, tres habían muerto en servicio, y los otros tres estaban sirviendo ${ }^{89}$ - , sino que, además, había servido hasta ese momento por casi 14 años. Sus primeros pasos dentro del mundo militar fueron - como casi toda una generación de navarros - en la infantería de la Armada, en el tercio de Lizarazu. Después se fue abriendo camino hasta llegar al grado de alférez, totalizando sus servicios en la Armada 9 años. En 1672 consiguió ser elegido capitán por el consejo de Guerra, y participó en una recluta en Galicia para Flandes ${ }^{90}$, en donde sirvió durante otros 4 años y 9 meses, siendo capitán dos veces. En febrero de 1677 consiguió una licencia del gobernador de los Países Bajos para volver a España, por lo que en el momento que se reunía el tercio se encontraba en Pamplona ${ }^{91}$.

De entre los capitanes elegidos cuyo historial conocemos, uno de ellos no disponía de servicios previos, otros dos no disponían de los servicios adecuados, y solo el alférez Francisco de Vargas y Beaumont reunía los requisitos. Había servido durante 13 años y 10 meses, y al contrario que la mayoría no era dueño de un palacio. Además, tampoco había forjado una carrera militar relacionada con el reino, sino que se había abierto camino primero en Extremadura y Flandes, en donde se había convertido en alférez. Durante la campaña de 1676 había caído prisionero de los franceses, por lo que, tras ser liberado, se encontraba recuperándose de una enfermedad en Pamplona. Hechos que le convertían en una excepción a la norma ${ }^{92}$.

Otro factor común era que casi todos los pretendientes estaban - por un motivo u otro-, presentes en Navarra. La única excepción fue uno de los capitanes -Francisco de Ibero- , que en ese momento servía como soldado aventajado en el ejercito de Cataluña. Sujeto que, aunque había gozado de una plaza de menor de edad en el Castillo de Pamplona — ante la posición de su padre, maestre de campo en la plaza—, oficialmente solo había servido 5 meses en Cataluña ${ }^{93}$.

86 Relación de servicios de Fausto Cruzat, 1717. AGI, Indiferente, 139 N.125.

87 Relaciones de servicios de Juan Cruzat, 1679 y 1696. Archivo Histórico Nacional (en adelante AHN), Estado (en adelante E), leg. 1289-2 nº 103 y AGS, GA, SM, leg. 40 f. 58.

88 Relaciones de servicio de Martín y Lorenzo de Ripalda, 1666 y 1678. AHN, E, leg. 1336-1 nº 141 y $1336-2 n^{\circ} 37$.

89 Memorial de Lorenzo Ripalda, Pamplona, 14 de mayo de 1677. ARGN, Guerra, leg. 4 nº 74.

90 Arzobispo de Santiago al rey, 4 de septiembre de 1672. AGS, GA, leg. 2284.

91 Relación de servicios de Lorenzo Ripalda, 1677. AGI, Indiferente, 125 N.146

92 Memorial del Francisco de Vargas, Pamplona, 12 de mayo de 1677. ARGN, Guerra, leg. 4 no 69.

93 Relación de servicios de Francisco de Íbero, s/f. AGS, GA, SM, leg. 21 f. 8. 
Respecto a la capacidad y veteranía de los oficiales que componían la unidad, la comparación nos permite ver las diferencias respecto a cualquier otra unidad que se reclutaba en Castilla. Si contrastamos los datos de los servicios de la oficialidad con los del tercio de Diego Salinas, reclutado en 1685 para servir en Navarra, los números hablan por sí solos. Los oficiales de dicha unidad reportaban de media 14,25 años de servicio — entre 7 casos $^{94}$-, mientras que los del tercio con que sirvió Navarra en 1677 era de 6,25 años —-sobre 6 casos-. Eso indica que los oficiales elegidos por el consejo de Guerra tenían más del doble de experiencia, y estaban más capacitados que los elegidos dentro de los servicios. Mientras que para los primeros un hito de idoneidad era la experiencia — que pesaba bastante en el conjunto, a pesar de que conozcamos casos en los que el consejo eligiera sujetos en base al nepotismo o la venalidad - en los servicios — además de la naturaleza - , pesaba más la tradición de servicio de las familias, o su pertenencia a un grupo reducido de miembros del brazo militar o de dueños de palacios de armería, que la experiencia personal de los candidatos.

El tercio llegó a Barcelona el 15 de junio. Tras varios días de descanso, partió hacía Gerona el día 27, pero tras pasar muestra se reconocía que faltaban 41 desertores, a los que se sumaban 22 enfermos en Barcelona y Gerona. En conjunto, antes de entrar en acción - a pesar de que no habían faltado las pagas - la unidad había perdido prácticamente uno de cada diez soldados. La actuación de la administración contra los desertores fue dura, al arcabucearse a dos de los cuatro capturados, alguno de los cuales también tenía delitos previos ${ }^{95}$. Pocos días después el tercio participó en la batalla del barranco de Espolla, el 4 de julio. Aunque no ocupó ningún puesto en la vanguardia, la unidad tuvo 10 muertos, 25 heridos y 3 prisioneros, quedando entre los últimos uno de los capitanes ${ }^{96}$. El resto de la campaña militar fue bastante tranquila en Cataluña, y no se desarrollaron operaciones más allá de las puramente defensivas, estando la unidad bien proveída de fondos. A finales de noviembre el servicio terminaba, dándose orden para reformar la unidad y que volviera a Navarra ${ }^{97}$.

La monarquía pretendía que el servicio se prorrogase, aunque fuera de menor cuantía. Al no conseguirlo, el consejo de Guerra intentó aprovechar que el tercio volvía habiendo incorporado entre sus filas a muchos forasteros —a los que había

94 CCG, 7 de mayo de 1685. AGS, GA, leg. 2652. Título de Maestre de Campo, 30 de junio de 1685. Patentes y suplimientos, mayo/junio 1685. AGS, GA, libro 387 f. 158 y ss. Relación de Servicios de Juan de Mendoza. AGS, GA, SM, leg. 44 f. 103.

95 Relación de las levas..., Madrid, 22 de junio de 1677. AGS, GA, leg. 2428. Aldasolo al reino, Gerona, 1 de julio de 1677. ARGN, Guerra, leg. 4 nº 79.

96 Relación de los oficiales..., Figueras, 12 de julio de 1677. AGS, GA, leg. 2377. Aldasolo al reino, Figueras, 6 de julio de 1677. ARGN, Guerra, leg. 4 nº 80 .

97 Disposiciones del consejo de Guerra, 30 de noviembre de 1677. AGS, GA, leg. 2378. Instrucciones sobre la retirada de los tercios, 10 de noviembre de 1677. AGS, GA, libro 345 f. 88 . Cuentas de Joseph de Aldasolo, 1677. ARGN, Guerra, leg. 5 nº 1. 
reclutado entre el resto de los soldados del ejército, que eran atraídos por las pagas seguras - , para intentar que éstos se alistasen en las compañías del presidio ${ }^{98}$.

A finales de 1677 se esperaba que Navarra renovase el servicio ${ }^{99}$, y a mediados de 1678 se intentó que el reino se comprometiese a reunir hombres, propuesta que terminó denegándose ${ }^{100}$. En 1684, la monarquía realizó un llamamiento, en previsión a otro golpe francés en Cataluña. Intentó que Navarra formara un Tercio de 600 infantes pagados por 6 meses - igual que en 1677-, para que combatiera en Cataluña. El virrey se mostró reacio, ya que afirmaba que sería mejor contribuir en dinero para las fortificaciones ${ }^{101}$. Una vez reunidas las Cortes - a mediados de marzo- empezaron a verse movimientos en la frontera, lo que desaconsejó la salida de tropas ${ }^{102}$. Las Cortes concedieron 24.000 ducados para las fortificaciones de Pamplona ${ }^{103}$. La petición de tercios no se volvería a producir durante el resto del reinado de Carlos II, y las Cortes solo aprobarían nuevos servicios económicos para las fortificaciones ${ }^{104}$.

\section{Reclutar sin las Cortes}

El reclutamiento administrativo en Navarra es un gran desconocido (Usunáriz, 2007, p. 309), ya que la mayoría de los trabajos no han profundizado en las fuentes administrativas de la monarquía. Pero el sistema se integró en la realidad navarra al menos desde finales del siglo XVI. En 1589, coincidiendo con las mayores necesidades bélicas producidas por la empresa de la Gran Armada, dos capitanes reclutaron en Navarra ${ }^{105}$. Al menos desde esas fechas parece que casi todos los años un capitán — de los 30 a 40 que reclutaban en España — se desplazaba a Navarra. La única par-

98 Rey a Fuensalida, Madrid, 10 de noviembre de 1677. AGS, GA, leg. 2389. Fuensalida al rey, Pamplona, 18 de noviembre de 1677 (dos de la misma fecha). AGS, GA, leg. 2398. Lorenzo Ripalda al reino, Gerona, 20 de octubre de 1677. Fuensalida al rey, Pamplona, 2 de noviembre de 1677. CCG, 6 y 29 de noviembre de 1677. AGS, GA, leg. 2376. Rey a Fuensalida, 10 de noviembre de 1677. AGS, GA, libro 345 f. 86v.

99 Rey a Monterrey, 6 de diciembre de 1677. AGS, GA, libro 345 f. 111v.

100 CCG, 28 de marzo de 1678. AGS, GA, leg. 2406.

101 Órdenes al Virrey, Madrid, 21 de diciembre de 1683 y 29 de enero de 1684. AGS, GA, libro 373 f. 143 y 160. CCG, 15 de enero de 1684. AGS, GA, leg. 2613.

102 Velandia a Navarra, Pamplona, 21 de marzo de 1684. Navarra al rey, Pamplona, 21 de marzo de 1684. Velandia al rey, Pamplona, 22 de marzo de 1684. AGRN, Guerra, leg. 5 n 18 . Navarra a Medinaceli, Pamplona, 21 de marzo de 1684. Medinaceli a Navarra, Madrid, 29 de marzo de 1684. AGRN, Guerra, leg. 5 n 19.

103 Proposición de Iñigo de Velandia a los Tres Estados de las cortes, 1684. AGRN, Guerra, leg. 5 $\mathrm{n}^{\mathrm{o}} 28$. Rey a Navarra, Madrid, 3 de julio, 1 de septiembre y 28 de noviembre de 1684. Navarra a Velandia, y su respuesta, Pamplona, 19 de julio de 1684. Velandía al rey, Pamplona, 7 y 9 de octubre de 1684. AGRN, Guerra, leg. 5 n 29.

104 Villena a las Cortes de Estella, 21 de noviembre de 1691. AGRN, Fortificaciones, leg. 1 n $^{\circ} 35$.

105 Patente de Pedro de Caritat, 20 de febrero de 1589. Elecciones de capitanes, 20 de febrero y 29 de mayo de 1589. Instrucciones a los comisarios, 15 de junio de 1589 . AGS, $G A$, libro 53 fs. 4, 30, 139 y 173 . 
ticularidad que diferenciaba el reclutamiento era que el consejo de Guerra intentaba que el capitán fuera navarro, lo que podía facilitar el enganche ${ }^{106}$. Entre 1603 y 1625 al menos 15 capitanes reclutaron en Navarra sin que eso supusiera gastos directos, o se obligará al reino a cubrir cupos ${ }^{107}$. Esto significaba que de media podían salir entre 100 y 200 voluntarios en cada campaña ${ }^{108}$.

La crisis del reclutamiento administrativo ante la falta de reclutas provocó en la década de 1630 la puesta en marcha de sistemas que pretendían implementar la colaboración local (MacKay, 2007; Rodríguez Hernández, 2011). Esto dejaba de lado la importancia de la centralización administrativa del consejo de Guerra, para que el virrey y el reino tuvieran una mayor importancia en las decisiones a cambio de unos mejores resultados. El dinero seguía llegando desde Castilla, pero las patentes en blanco daban vía a libre a los mediadores locales para la elección de capitanes, algo que podemos ver en Navarra al menos desde $1634^{109}$ (Gallastegui, 1990, p. 82).

Durante los primeros años del reinado de Carlos II se continuó viendo Navarra como un lugar donde poder conseguir reclutas debido a las pocas levas que allí se desarrollaban. En 1665 se esperaba que en Navarra se pudieran reclutar 300 hombres para el ejército de Extremadura. Al final, debido a que se consideraba que reunir hasta 500 hombres en Castilla tendría un coste menor, y que el virrey afirmaba que «los naturales no se inclinan de ninguna manera a salir de sus casas para la guerra», la leva no se produjo ${ }^{110}$. Mejor suerte correría la petición realizada durante 1667. Al inicio de la Guerra de Devolución se temió un ataque ${ }^{111}$. Se necesitaban hombres en Fuenterrabía, la plaza más amenazada, de ahí que se intentarán reclutar en Navarra. En esa ocasión, se consiguió reunir a 270 hombres en el discurso de 5 meses, gastándose 3.000 escudos $^{112}$.

En 1667, el consejo de Estado valoró la posibilidad de que se realizasen reclutas para Flandes dentro de un proyecto más amplio ${ }^{113}$. La idea se retomó en 1669 , cuando el consejo de Guerra escribió al virrey para que indagase sobre el

106 CCG, 22 de febrero de 1617. AGS, GA, leg. 819.

107 Instrucciones y nombramientos, varias fechas. AGS, GA, libro 96.

108 Aramayona al rey, Pamplona, 25 y 30 de diciembre de 1616; y 7 de abril de 1617. AGS, GA, legs. 816 y 819 .

109 CCG, 10 de marzo de 1634. AGS, GA, leg. 1095.

110 Rey a San Germán, 8 de febrero y 20 de mayo de 1665. AGS, GA, libro 264 f. 138 y 145. Junta de levas, 5 de marzo de 1665. San Germán al rey, Pamplona, 5 de febrero de 1665. AGS, GA, legs. 2083 y 2109.

111 CCE, 18 de agosto de 1667. San Germán al rey, Pamplona, 28 de julio de 1667. AGS, E, leg. 2686. 112 CCG, 17 de diciembre de 1666. AGS, GA, leg. 2112. Relación del dinero que es menester, s/f. AGS, GA, leg. 2157. Diego Caballero al rey, Pamplona, 29 de agosto de 1669. AGS, GA, leg. 2195. Francisco Vitor al rey, Fuenterrabía, 19 de agosto de 1667. Guipúzcoa al rey, 13 de agosto de 1667. AGS, GA, leg. 2159.

113 Castel-Rodrigo al rey, Bruselas, 20 de marzo de 1667. AGS, E, leg. 2106. 
número de hombres que podría reclutar y los costes ${ }^{114}$. Se estipuló que se podrían reunir 300 hombres, a los que se vestiría y conduciría a los puertos con un coste de 4.000 ducados de plata, si bien se anuló la medida, ya que habían pasado demasiados hombres a Flandes ${ }^{115}$. Los mismos resultados tuvieron otras propuestas a lo largo de la siguiente década. A finales de 1673 se volvió a intentar reclutar para la dotación de infantería de la Armada, y poco después se intentó reunir 200 hombres para Flandes. Proyectos que no se materializarían, ya fuera porque se consideró inapropiado sacar hombres de Navarra en tiempo de guerra, o porque los costes y las posibilidades lo desaconsejaron ${ }^{116}$. La única leva efectiva durante toda la década se produjo en 1670, en tiempo de paz, cuando el consejo de Guerra envió a uno de los diez capitanes que reunían efectivos para Cataluña, además de 3.000 escudos de plata para cubrir costes ${ }^{117}$.

En 1680 se planificó reclutar 2.000 españoles para Flandes, de los cuales 600 se reunirían en Navarra ${ }^{118}$. Las primeras indagaciones por parte del virrey se centraron en encontrar las personas de «autoridad y séquito» para que se encargasen de levantar un tercio de diez compañías a cargo de la real hacienda, estipulándose el coste en 42.000 escudos. El virrey negoció con ocho sujetos para que a cambio de las patentes reuniesen los hombres. Todos los propuestos provenían de la baja nobleza navarra, aunque no todos habían servido formalmente en el ejército el tiempo suficiente como para convertirse en oficiales. Pronto se vio que se debían ensanchar los distritos de reclutamiento a La Rioja, el norte de Burgos y Álava, y que los costes ascendían a 150.000 reales de plata, incluido el transporte ${ }^{119}$. En Madrid las peticiones parecían demasiado elevadas. Además, debido al ensanche, el consejo de Guerra indicaba que los agraciados con las patentes debían ser también de las nuevas zonas de reclutamiento: 400 hombres se reclutarían en Navarra, y otros 200 en Logroño y el norte de Burgos ${ }^{120}$. La nueva orden de reclutar — sin formar un tercio- daba al traste con todo, ya que el virrey afirmaba: «...no abra cavallero que se encargue alebantar

114 Informe sobre el estado de Flandes, Madrid, 3 de junio de 1669. AGS, E, leg. 2110. San Germán al rey, Pamplona, 18 de agosto de 1667. AGS, GA, leg. 2157.

115 Diego Caballero al rey, Pamplona, 29 de agosto de 1669. CCG, 11 de septiembre de 1669. AGS, $G A$, leg. 2195. Rey a Diego Caballero, Madrid, 13 de agosto de 1669. AGS, GA, libro 300 f.109.

116 CCG, 4 de diciembre de 1673. AGS, GA, leg. 2287. Diego Sarmiento al rey, Madrid, 14 de noviembre de 1673. AGS, GA, leg. 2285. Orden Real, 22 de noviembre de 1673. AGS, GA, leg. 2297. Informe para ver en el consejo, 1674. AGS, GA, leg. 2242.

117 Rey a Diego Caballero, 24 de abril de 1670. Patentes para las compañías, 24 de abril de 1670. AGS, GA, libro 264 f. 218 y 219. CCG, 13 de marzo de1670. Diego Sarmiento al rey, Madrid, 4 de marzo de 1670. AGS, GA, leg. 2219.

118 CCG, 12 de enero y 21 de febrero de 1680. AGS, GA, leg. 2476.

119 CCG, 23 de febrero y 18 de marzo de 1680. Lista de los caballeros, s/f. AGS, GA, leg. 2476. Orden Real, 7 de febrero de 1680. Memoria de los partidos, s/f. AGS, GA, legs. 2497 y 2498.

120 CCG, 12 de enero y 21 de febrero de 1680. Corregidor de Logroño al rey, 6 de febrero de 1680. AGS, GA, leg. 2476. Relación de los sujetos que pretenden, Logroño, 1680. AGS, GA, leg. 2496. 
el numero de cien hombres para su compañía, por la dificultad de juntarlos». Finalmente, el virrey escribió que veía difícil la recluta, ya que, al no formarse un tercio, la nobleza y su gente no se alistaría, por lo que no podía asegurar que se reunieran 50 hombres. Ante la situación - y la falta general de dinero tras la devaluación del vellón-, se anularon las órdenes ${ }^{121}$.

Desde 1680 no se volvió a intentar reclutar hombres. Los motivos estaban en el hecho de que el reino se convirtió en lugar de llegada de tropas desde Castilla ante la amenaza francesa. Tampoco ayudaba el superior coste de leva respecto a Castilla, y la costumbre de que los oficiales fueran navarros para que la leva tuviera éxito. Condicionantes que también influyeron en el desenlace, e hicieron que apenas se reunieran hombres, por lo que no es de extrañar que en muchas ocasiones se pensara que en Navarra se podrían encontrar voluntarios con facilidad ${ }^{122}$. En balance el resultado del reclutamiento directo fue decepcionante, unos 370 hombres en todo el reinado, la ratio más baja de todo el siglo.

\section{Conclusiones}

Durante el reinado de Carlos II, Navarra volvió a estar amenazada por Francia. Una invasión francesa parecía inminente, pero los enfrentamientos fronterizos fueron escasos y a pequeña escala. Es cierto que en 1672 (asalto a la villa de Espinal) ${ }^{123}$ y 1684 (San Salvador de Ibañeta) ${ }^{124}$ el suelo navarro fue invadido, pero las acciones francesas fueron limitadas y breves. Los miedos a una invasión, en cambio, fueron permanentes, especialmente desde la década de 1680, y el alojamiento de tropas francesas al otro lado de la frontera fue visto como una seria amenaza ${ }^{125}$. La reacción por parte de la monarquía en las décadas finales del siglo fue dotar al reino de mayor capacidad defensiva destinando más hombres. Desde 1685 se destinaron dos tercios profesionales, cantidad, que, con diversas fluctuaciones, se mantuvo hasta que las necesidades bélicas de otras regiones hicieron que la mayor parte de estas tropas abandonasen Navarra en 1697. De hecho, solo durante la Guerra de los Nueve Años (1689-97), Navarra recibió 5.160 reclutas llegados fundamentalmente de Castilla y Galicia (Rodríguez Hernández, 2018, p. 1173).

121 CCG, 18 de marzo de 1680. AGS, GA, leg. 2476.

122 Memorial de Gaspar de Santa Cruz, 8 de junio de 1667. Diego Sarmiento al rey, Madrid, 9 de junio de 1667. AGS, GA, leg. 2152. Melchor Portocarrero al rey, 23 de diciembre de 1677. AGS, GA, leg. 2395. Rey a Pedro de Aragón, 5 y 11 de noviembre de 1677. AGS, GA, libro 345 f. 84 y 97.

123 Instrucción al virrey, Madrid, 3 de enero de 1673. AHN, E, libro 272 f. 1v. CCE, 9 de enero de 1673. AGS, E, leg. 2695.

124 Velandia al rey, Pamplona, 22 de marzo de 1684. AGRN, Guerra, leg. 5 nº 18.

125 CCG, 24 de noviembre de 1681 y 4 de febrero de 1682. AGS, GA, legs. 2512 y 2543. 
Como hemos visto, los navarros eran movilizados si llegaba la ocasión, pero durante este periodo analizado nunca se llamó a servir a toda la población bajo el sistema de apellido. Los remisionados, y otros sistemas antiguos, eran tropas sobre el papel; los cuatro tercios — aunque se movilizaron—, siempre fue por pocas semanas, no participando en acciones destacadas; y la movilización de las milicias fronterizas fue escasa y poco sostenida en el tiempo, ya que nunca se produjo una invasión. Es decir, la participación de los navarros en su defensa fue limitada. Por otro lado, la salida de navarros para combatir en otras regiones fue escasa. Como hemos visto, el rey solo reclutó cerca de 370 voluntarios, y desde la década de 1680 nunca lo volvió a intentar. Respecto a los servicios de tropas concedidos por las Cortes, el único fue en 1677 - 660 hombres pagados por 6 meses - , tras tres años de relativa calma en la frontera. Un escaso aporte si tenemos en cuenta que desde 1642 a 1662 Navarra sirvió con más de 5.000 efectivos. Los datos de movilización nos indican la importancia de los fueros como salvaguarda a la hora de ser presionados con nuevos servicios, demostrando que la tensión fronteriza en el último cuarto del siglo restringió aún más las peticiones de tropas para otros frentes. Paradigmáticamente, a pesar de esto, Navarra movilizó menos tropas que en otros periodos previos. Ciertamente los navarros aportaron más dinero para las fortificaciones de Pamplona - como bien alegaronpero si vamos a las cuentas de gasto, dichas aportaciones sólo son una pequeña parte del coste total de la defensa de Navarra ${ }^{126}$.

Otra pregunta que debemos formularnos es si la aportación navarra - aunque fuera acorde con los fueros - fue suficiente en vista de la amenaza. En este punto, conviene comparar con otros ámbitos, si bien las comparaciones nunca podrán ser del todo precisas ante las diferencias poblacionales ente reinos, el contexto bélico, o los ordenamientos legales de cada uno. La frontera pirenaica de Aragón también fue presionada durante este periodo por los franceses, y sin embargo siguió aportando periódicamente tropas en el frente catalán por medio de servicios - levados y pagados- en tiempo de guerra. Durante el periodo de 1678-85 estos ascendían — sobre el papel-a 1.500 efectivos, aunque la cifra siempre estuvo lejos de cumplirse (Espino, 2004 y 2007). Guipúzcoa, ante la amenaza de una invasión francesa levantó tres compañías de sus naturales durante 1666. En 1674 reclutó 1.000 hombres durante otros tres meses; y en 1684 envió 200 de refuerzo a Fuenterrabía, encargándose siempre de movilizar y pagar a las tropas de refuerzo ${ }^{127}$.

126 Cuentas de Navarra, 1687-1696. AGS, CMC3, leg. 1393.

127 Carta del gobernador, Fuenterrabía, 12 de julio de 1667. CCG, 23 de mayo de 1674. Cartas de la provincia de Guipúzcoa, Hernani, 20 de junio y 5 de julio de 1674. AGS, GA, legs. 2154, 2301 y 2302. Carta de Diego Sarmiento, Madrid, 13 de mayo de 1674. Orden Real, Madrid, 24 de noviembre de 1674. AGS, GA, leg. 2315. Orden a la provincia de Guipúzcoa, Madrid, 28 de marzo de 1684. AGS, GA, libro 373 f.212. 
También debemos comparar el caso navarro con la defensa de la denominada Frontera de Castilla — que abarcaba la frontera de las actuales provincias de Zamora y Salamanca con Portugal - en el periodo de la Guerra de Restauración Portuguesa (1640-1668). Durante ese conflicto, dicha frontera — con unos $300 \mathrm{~km}$ de extensión, y orográficamente más abierta que la pirenaica - estaba defendida fundamentalmente por sus naturales. Una foto fija de 1660 nos indica que en conjunto las plazas de Ciudad Rodrigo, Zamora y Puebla de Sanabria tenían asignados 4.363 infantes y 554 caballos $^{128}$. Aunque la caballería solía ser profesional, la infantería estaba compuesta por vecinos obligados a prestar servicio. De cada 10 vecinos, uno debía enviarse a servir al tercio fijo de la frontera de su distrito - en donde debía servir todo el año-, y otro quedaba alistado en las compañías de milicias de socorro, que sólo actuaban en caso de verdadera necesidad. El reemplazo de las tropas era anual, formalizándose un verdadero sistema de quintas ${ }^{129}$. En muchos casos ni los hidalgos se libraban, haciendo que muchos mozos solteros se casaran apresuradamente intentado así tener más opciones para librarse ${ }^{130}$. La carga de la actividad militar era pesada para los naturales, ya que también debían contribuir con impuestos extraordinarios para la invernada de las tropas ${ }^{131}$.

Después de esta comparativa con otros territorios de frontera, parece evidente que los navarros no soportaron una enorme presión militar. La monarquía no delegó al completo la defensa de la región a sus habitantes, ni los gastos. Los fueros actuaron como salvaguarda, a lo que ayudaron las fórmulas tradicionales de movilización militar, que no se modificaron sustancialmente a pesar de que hundían sus raíces en el medievo. La movilización de toda la población en caso de invasión de poco servía a estas alturas, en un contexto europeo de ejércitos profesionales. Se realizaron intentos de extender los sistemas de movilización militar practicados en Castilla (Rodríguez Hernández, 2011 y 2012), aunque sin éxito (Rodríguez Garraza, 2007; Rodríguez y Díaz, 2018). La solución hallada fue la conversión de este sistema en cuatro tercios de milicias reglados en 1638, que se convirtieron en un verdadero seguro para los virreyes en caso de invasión, ya que su movilización dejó de ser dependiente de la Diputación, mejorando la capacidad de acción de los virreyes a la hora de defender Navarra durante el periodo. Una mejora relativa, ya que se movilizaron pocas veces.

128 Relación de las plazas de las fronteras de Castilla la Vieja..., Zamora, 6 de abril de 1660. AGS, GA, leg. 1954.

129 Instrucciones de reemplazo, 11 de abril y 13 de diciembre de 1651 . AGS, GA, libro 216 fs. 112 y 211.

130 Instrucciones al marqués de Tábara, 22 de junio de 1654. AGS, GA, libro 234 f. 265.

131 Relación del dinero necesario..., Zamora, 25 de noviembre de 1652. AGS, GA, leg. 1821. 
El reinado de Carlos II se caracterizó, en suma, por los escasos servicios del reino, caracterizado por la historiografía reciente como una de las épocas doradas del neoforalismo, ante las moderadas aportaciones fiscales y humanas del periodo (Floristán, 2015). Idea que se reafirma tras el análisis sobre la movilización militar y la defensa de Navarra realizado en este texto.

\section{AGRADECIMIENTOS}

Trabajo integrado dentro del proyecto HAR2016-80673-P. La edición de este trabajo ha sido posible gracias a la ayuda del Programa de Grupos de Potencial Crecemento concedida por la Consellería de Cultura, Educación e Universidade da Xunta de Galicia al GI-1921 de la USC (Referencia: GPC, ED 431B 2021/06). 


\section{Bibliografía}

ChAVARríA, Fernando (2006), Monarquía fronteriza: Guerra, linaje y comunidad en la España Moderna (Navarra, siglo XVI), Florencia, European University Institute [Tesis doctoral inédita].

Coloma García, Virginia (1995), «Navarra y la defensa de la monarquía en los reinados de Felipe III y Felipe IV (1598-1665)», Príncipe de Viana $\mathrm{n}^{\circ}$ 204, pp. 163-182.

DréVILlon, Hervé (2015), Le Roi absolu. Louis XIV et les Français (1661-1715), París, Belín, 2015.

Escribano PÁez, José Miguel (2015), El Coste de la Defensa. Administración y financiación militar en Navarra durante la primera mitad del Siglo XVI, Pamplona, Gobierno de Navarra.

Espino LóPEZ, Antonio (2004), «El esfuerzo de guerra de la Corona de Aragón durante el reinado de Carlos II, 1665-1700. Los servicios de tropas», Revista de Historia Moderna, $\mathrm{n}^{\circ}$ 22, pp. 209-250. <https://doi.org/10.14198/rhm2004.22.07>.

Espino LóPEz, Antonio (2007), Guerra, fisco y fueros. La defensa de la Corona de Aragón en tiempos de Carlos II, 1665-1700, Valencia, Universidad de Valencia.

Espino López, Antonio (2018), «La frontera de Navarra durante el reinado de Carlos II. La acción virreinal y el problema de la defensa», Príncipe de Viana, nº 271, pp. 527-552.

FernÁNDEZ de LARREA, Jon Andoni (1992), Guerra y sociedad en Navarra durante la Edad Media, Bilbao, Universidad del País Vasco.

FernÁNDEZ de LARREA, Jon Andoni (2018), «The kingdom of Navarre», en Francisco García Fitz y João Gouveia Monteiro (eds.), War in the Iberian Peninsula 700-1600, Oxon, Routledge, pp. 175-200. <https://doi.org/10.4324/9781315200378-5>.

Floristán Imízcoz, Alfredo (1984), «Repercusiones de la rebelión y guerra de Cataluña en Navarra. Las Cortes de Pamplona de 1642», en Primer Congrés d'Història Moderna de Catalunya, Barcelona, Universidad de Barcelona, vol. 2, pp. 181-188.

Floristán ImízCoz, Alfredo (1991), La monarquía española y el gobierno del Reino de Navarra, 1512-1808. Comentario de textos históricos, Pamplona, Príncipe de Viana.

Floristán Imízcoz, Alfredo (2015), «Neoforalismo, nuevos fueros y conquistas. Navarra en la Monarquía de Carlos II», en García García, Bernardo J. y Álvarez-Ossorio Alvariño, Antonio (eds.), Visperas de sucesión. Europa y la Monarquía de Carlos II, Madrid, Fundación Carlos de Amberes, pp. 81-109. 
Fuero General de Navarra, (edición de 1869), Pamplona, imprenta provincial.

Gallastegui Ucín, Javier (1990), Navarra a través de la correspondencia de los virreyes (1598-1648), Pamplona, Gobierno de Navarra.

García Miguel, Virginia (1988), «La donación de un tercio navarro para la guerra de Cataluña en 1642», Príncipe de Viana, nº 9, pp. 121-130.

Herrera Reviriego, José Miguel (2015), «Nobleza y comercio transoceánico: el camino del gobernador Fausto Cruzat y Góngora», Millars: Espai i historia, vol. 38, $\mathrm{n}^{\mathrm{o}}$ 1, pp. 157-176. <https://doi.org/10.6035/millars.2015.38.7>.

IdoATe, Florencio (1981), Esfuerzo bélico de Navarra en el siglo XVI, Pamplona, Diputación.

Jimeno Aranguren, Roldán (2007), «Servicio de armas en los fueros medievales de Vasconia: fonsado/hueste, cabalgada y apellido», Iura Vasconiae, $\mathrm{n}^{\circ} 4$, pp. 33-66.

MACKAY, Ruth (2007), Los Límites de la autoridad real. Resistencia y obediencia en la Castilla del siglo XVII, Valladolid, Junta de Castilla y León.

Martínez ArCe, María Dolores (2002), Navarra y el ejército en el conflictivo siglo XVII, Pamplona, Bodegas Irache.

Novíssima recopilación de las leyes de el Reino de Navarra: hechas en sus Cortes Generales desde el año de 1512 hasta el de 1716 inclusive, (1735) Pamplona, 2 vols.

Ostolaza Elizondo, María Isabel (2000), «Administración del reino de Navarra en la etapa de los Austrias», Hispania, vol. 60, no 205, pp. 563-596. <https://doi. org/10.3989/hispania.2000.v60.i205.554>.

Pascual Sarría, Francisco Luis (2003), «Las obligaciones militares establecidas en los ordenamientos de las cortes castellano-leonesas durante los siglos XIII y XIV», Revista de Estudios Histórico-Jurídicos, no 25, pp. 147-185. <https:// doi.org/10.4067/s0716-54552003002500005>.

Quatrefages, René (1996), La Revolución Militar Moderna. El Crisol Español, Madrid, Ministerio de Defensa.

Rodríguez Garraza, Rodrigo (1991), «Navarra y la Administración central (16371648)», Cuadernos de Historia Moderna, no 11, pp. 149-176.

Rodríguez Garraza, Rodrigo (2007), «Los intentos de extensión en Navarra del servicio militar (siglo XVII)», Iura Vasconiae nº 4, pp.367-387.

Rodríguez Hernández, Antonio José (2011), Los Tambores de Marte: el reclutamiento en Castilla durante la segunda mitad del siglo XVII (1648-1700), Valladolid, Universidad de Valladolid. 
Rodríguez Hernández, Antonio José (2012), «Los primeros ejércitos peninsulares y su influencia en la formación del Estado Moderno durante el siglo XVII», en González Enciso, Agustín (ed.), Un Estado Militar. España, 1650-1820, Madrid, San Sebastián de los Reyes, pp. 19-64.

Rodríguez Hernández, Antonio José (2018), «La frontera navarra durante la guerra de los Nueve Años (1688-1697): defensa y movilización militar», Príncipe de Viana, no 272, pp. 1163-1178.

Rodríguez Hernández, Antonio José y Díaz Paredes, Aitor (2018), «Revisitando el neoforalismo: Reclutamiento en Navarra en tiempo de paz en la frontera (1659-1670)», en Torres, Rafael (ed.), Studium, magisterium et amicitia. Homenaje al profesor Agustín González Enciso, Pamplona, Eunate, pp. 265-275.

SAlcedo Izu, Joaquín (1974), Atribuciones de la Diputación del Reino de Navarra, Pamplona, Diputación de Navarra.

Sanz Camañes, Porfirio (1997), Política, hacienda y milicia en el Aragón de los últimos Austrias 1640-1680, Zaragoza, Institución Fernando el Católico.

Solano Camón, Enrique (1987), Poder monárquico y estado pactista (1626-1652). Los aragoneses ante la Unión de Armas, Zaragoza, Institución Fernando el Católico.

UsunÁriz Garayoa, Jesús María (2007), «Soldados, sociedad y política en un reino de frontera: Navarra siglos XVI y XVII», Iura Vasconiae no 4, pp. 285-325.

Usunáriz Garayoa, Jesús María (2012), Historia Breve de Navarra, Madrid, Sílex. 